\title{
PENGARUH SOCIAL MEDIA, ELECTRONIC WORD OF MOUTH, BRAND ATTITUDE TERHADAP PURCHASE INTENTION KONSUMEN PADA SITUS ONLINE SHOPEE ID
}

\author{
Vivian Angelica \\ Program Studi Magister Manajemen Universitas Tarumanagara \\ vian.angelicaa@@gmail.com
}

Masuk : 02-12-2020, revisi : 21-12-2020, diterima untuk diterbitkan : 22-12-2020

\begin{abstract}
This study aims to determine the effect of social media, electronic word of mouth and brand attitude of purchase intention on consumers on the site online shopee id. This research was conducted on consumers on the site online shopee id. The analysis method uses multiple linear analysis methods where the data can be obtained by distributing questionnaires with 200 respondents. This type of research is quantitative and uses the SPSS program version 25 . The results of the hypothesis show that there is a significant influence on social media, electronic word of mouth and brand attitudes on purchase intentions on consumers on the site online shopee id. Of the three variables, the one that most influences purchase intention is the brand attitude variable.
\end{abstract}

Keywords: Social-Media, Electronic Word of Mouth, Brand Attitude, Purchase Intention

\begin{abstract}
Abstrak: Penelitian ini bertujuan untuk mengetahui pengaruh social media, electronic word of mouth dan brand attitude terhadap purchase intention pada konsumen di situs online shopee id. Peneitian ini dilakukan kepada konsumen di situs online shopee id. Metode analisis menggunakan metode analisis linier berganda dimana data didapat dengan menyebar kuisoner dengan responden sebanyak 200 orang responden. Jenis penelitian adalah kuantitatif dan menggunakan program SPSS versi 25 . Hasil hipotesis penelitian menunjukan bahwa terdapat pengaruh yang signifikan social media, electronic word of mouth dan brand attitude terhadap purchase intention pada konsumen di situs online shopee id. Dari ketiga variabel tersebut, yang paling mempengaruhi purchase intention adalah variabel brand attitude.

Kata kunci: Sosial Media, Electronic Word of Mouth, Brand Attitude, Purchase Intention
\end{abstract}

\section{PENDAHULUAN}

Perkembangan internet di era sekarang bukanlah hal yang asing lagi, abad ini dikenal dengan era revolusi industri 4.0, siapa saja dapat mengakses dan mendapatkan informasi dengan perkembangan teknologi dengan informasi yang ada didukung dengan lahirnya alat komunikasi pendukung yaitu smartphone atau social media. Penggunaan social media digunakan oleh masyarakat dalam melakukan banyak aktivitas mulai dari entertainment, melakukan bisnis, mencari info atau aktivitas lainnya.

Perkembangan teknologi komunikasi serta informasi yang pesat dan cepat, membuat segalanya hal harus dapat dilakukan dengan mudah termasuk akses informasi, informasi tersebut dapat diperoleh dengan mudah asal terhubung dengan jaringan internet. Sehubungan dengan hal tersebut purchase intention adalah hal yang sangat penting untuk diperhatikan Menurut pendapat Henry Assael dalam (Semuel \& Setiawan, 2018) purchase intention adalah kondisi dimana konsumen berniat untuk membeli sebuah produk/jasa yang memiliki harapan tertinggi.

Purchase intention dipengaruhi beberapa faktor. Menurut Prasad et al (2019). purchase intention dipengaruhi oleh social media dan electronic word of mouth serta mempunyai hubungan yang positif terhadap purchase intention. Faktor lainnya yang menpegaruhi purchase intention adalah brand attitude Menurut Abzari et al., 2014 The attitude of customer toward a 
brand has a significant effect on its purchase intention, as brand attitude is the most important determinant of purchase intention. Definisi lain Menurut Shekhar (2017) menjelaskan bahwa brand attitude berarti evaluasi merek konsumen secara keseluruhan. Sikap merek memegang peranan penting karena menjadi dasar perilaku konsumen yaitu pemilihan merek. Tujuan penelitian ini untuk mengetahui pengaruh social media, electronic word of mouth, brand attitude terhadap purchase intention. Hasil penelitian ini diharapkan agar perusahaan semakin memperhatikan faktor social media, electronic word of mouth, brand attitude terhadap purchase intention dalam kegiatan operasional situs online shopee id hal ini dikarenakan ketiga variabel tersebut diketahui mempunyai pengaruh dalam menciptakan purchase intention terhadap pembeli maupun calon pembeli.

\section{TELAAH KEPUSTAKAAN Social Media}

Menurut Kotler dan Keller (2016) adalah"online activites and programs designes toengage customers or prospects and directly or indirectly raise awareness, improve image, or elicit sales of products and services" Media sosial merupakan suatu aktivitas komunikasi pemasaran yang menggunakan media elektronik (online) dalam menarik konsumen atau perusahaan dalam berbagai bentuk (gambar, tulisan, dll) untuk meningkatkan kesadaran, citra perusahaan,dan untuk meningkatkan penjualan. Menurut Prasad et al (2019). Mengemukakan bahwa social media dan electronic word of mouth memiliki hubungan yang positif terhadap purchase intention.

\section{Electronic Word Of Mouth (EWOM)}

Menurut Arwiedya dalam Widagdo \& Saputri, (2017) media promosi yang berpengaruh terhadap keputusan pembelian salah satunya ialah online word of mouth dengan mengatakan bahwa Word of mouth adalah komunikasi interpersonal antara dua bahkan lebih individu seperti anggota kelompok referensi atau konsumen dan tenaga penjual dimana semua orang mempunyai pengaruh atas pembelian terus menerus melalui suatu komunikasi sedangkan word of mouth online adalah proses word of mouth dengan menggunakan media internet atau website. Menurut Prasad et al (2019). Mengemukakan bahwa social media dan electronic word of mouth memiliki hubungan yang positif terhadap purchase intention .

\section{Brand Atittude}

Assael Dalam Timpal, Lapian, \& Rate, (2016) mengatakan bahwa Brand Attitude adalah evaluasi keseluruhan konsumen terhadap merek, dalam model ekuitas merek ditemukan bahwa peningkatan pangsa pasar terjadi ketika sikap terhadap merek makin positif. Kudeshia,C., \& Kumar, A. (2017) mengatakan bahwa brand atittude berpengaruh positif terhadap purchase intention.

\section{Purchase Intention}

Purchase Intention adalah selera masing-masing orang yang menjadi dasar pemilihan sesuatu, minat membeli menunjukkan pada kecenderungan untuk lebih menyukai produk dengan merek tertentu (Kotler dan Keller, 2012). Peneliti menilai purchase intention adalah tindakan dari calon konsumen maupun konsumen untuk membeli suatu produk yang timbul dari dorongan pribadi untuk memenuhi kebutuhan.

\section{Kerangka Pemikiran}

Dasar pemikiran dan fokus dari penelitian ini adalah mengkaji pengaruh dari variabelvariabel Independen yaitu Social Media, Electronic Word Of Mouth dan Brand Atittude yang memiliki pengaruh terhadap Purchase Intention sebagai variabel Dependen Pada Konsumen Situs Online Shopee Id Berikut ini adalah model kerangka pemikiran pada penelitian ini 


\section{Gambar 1}

Kerangka Pemikiran

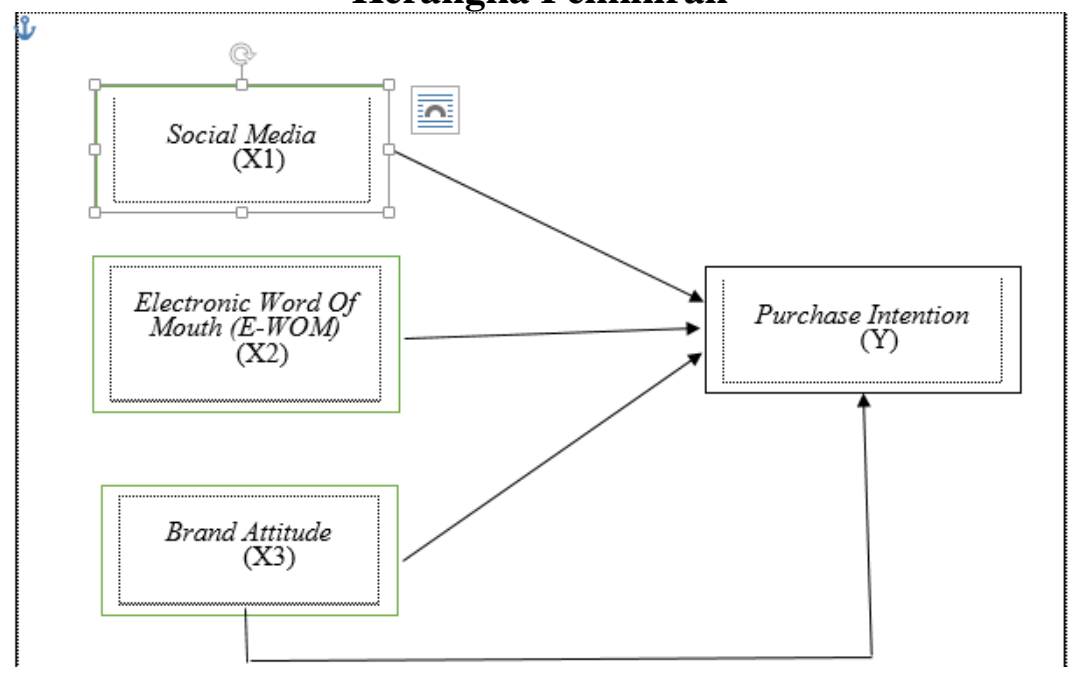

\section{Hipotesis Penelitian}

Berdasarkan kerangka pemikiran, maka hipotesis dalam penelitian ini adalah sebagai berikut :

\section{Hipotesis 1}

H0: Social Media tidak berpengaruh secara signifikan terhadap Purchase Intention

H1: Social Media berpengaruh secara signifikan terhadap Purchase Intention

\section{Hipotesis 2}

H0: Electronic Word of Mouth (E-WOM) tidak berpengaruh secara signifikan terhadap Purchase Intention

H1: Electronic Word Of Mouth (E-WOM) berpengaruh secara signifikan terhadap Purchase Intention

\section{Hipotesis 3}

H0: Brand Attitude tidak berpengaruh secara signifikan terhadap Purchase Intention

H1: Brand Attitude berpengaruh secara signifikan terhadap Purchase Intention

\section{Hipotesis 4}

H0: Social Media, Electronic Word Of Mouth dan Brand Attitude secara simultan tidak berpengaruh secara signifikan terhadap Purchase Intention

H1: Social Media, Electronic Word Of Mouth dan Brand Attitude secara simultan berpengaruh secara signifikan terhadap Purchase Intention

\section{METODE PENELITIAN}

Populasi dalam penelitian ini adalah orang yang merupakan Konsumen Situs Online Shopee Id. Dengan sampel penelitian adalah 200 orang. Metode pengambilan sampel yang digunakan nonprobability sampling dengan purposive sampling. Berdasarkan data yang terkumpul, mayoritas karakteristik responden pada penelitian ini adalah Wanita (64\%) berusia 20-30 tahun (75\%) yang berpenghasilan rata-rata di atas Rp. 2.500 .000 (44\%).

Pada penelitian ini, variabel Social Media, Electronic Word Of Mouth, Brand Attitude. merupakan variabel independent, sedangkan purchase intention adalah variabel dependent. Untuk mengukur variabel ini, menggunakan Skala Likert 5 poin dengan 1 menunjukan "sangat tidak setuju" dan 5 menunjukan "sangat setuju". Metode analisis data yang digunakan adalah analisis regresi ganda. Sedangkan, untuk uji asumsi seperti uji normalitas, uji multikolinieritas dan uji heteroskedastisitas telah dilakukan sebelumnya dan hasilnya menunjukan semua uji asumsi sudah terpenuhi. Pengujian dalam penelitian ini menggunakan program SPSS 25. Taraf signifikansi yang digunakan dalam penelitian ini adalah 0,05 .

Tabel ini dibawah ini menunjukan pengukuran masing-masing variabel dan sumbernya : 
Tabel 1

Variabel dan Pengukuran

\begin{tabular}{|l|c|c|}
\hline \multicolumn{1}{|c|}{ Variabel } & $\begin{array}{c}\text { Jumlah } \\
\text { item }\end{array}$ & Sumber \\
\hline $\begin{array}{l}\text { Variabel Independent } \\
\text { 1. Social Media }\end{array}$ & 8 & $\begin{array}{c}\text { Prasad et al. (2019) } \\
\text { Bambauer-Sachse and Mangold, 2011; Jalilvand and Samiei, } \\
\text { 2012 }\end{array}$ \\
$\begin{array}{l}\text { 2. Electronic Word Of } \\
\text { Mouth }\end{array}$ & 11 & Bambauer-Sachse and Mangold, 2011; Goyette et al.,2010) \\
$\begin{array}{l}\text { 3. Brand Atittude } \\
\begin{array}{l}\text { Variabel Independent } \\
\text { 1. Purchase Intention }\end{array}\end{array}$ & 7 & Schivinski and Dabrowski, 2014; Tang and Xiao, 2011. \\
Abzari, Et al., 2014
\end{tabular}

ANALISA DAN PEMBAHASAN

Tabel 2

Hasil Pengujian Hipotesis

\begin{tabular}{|c|c|c|c|c|}
\hline & Hipotesis & $\begin{array}{c}\text { Std. } \\
\text { Coefisien }\end{array}$ & Sig & Kesimpulan \\
\hline H1 & $\begin{array}{c}\text { Terdapat pengaruh positif social media terhadap purchase } \\
\text { intention }\end{array}$ & 0,296 & 0.000 & Ho ditolak \\
\hline H2 & $\begin{array}{c}\text { Terdapat pengaruh positif electronic word of mouth terhadap } \\
\text { purchase intention }\end{array}$ & 0,176 & 0.000 & Ho ditolak \\
\hline H3 & $\begin{array}{c}\text { Terdapat pengaruh positif brand atittude terhadap purchase } \\
\text { intention }\end{array}$ & 0,397 & 0.000 & Ho ditolak \\
\hline
\end{tabular}

Berdasarkan hasil pengujian hipotesis pada model 1, maka dapat disimpulkan bahwa social media, electronic word of mouth, brand atittude berpengaruh positif terhadap purchase intention. Ini berarti konsumen memiliki tingkat pembelian/ niat pembelian yang cukup tinggi terhadap produk/merk yang ditawarkan di situs online shoppe.id karena adanya kesadaran akan social media, electronic word of mouth, brand atittude yang baik. Hipotesis H1 ini sesuai dengan penelitian Prasad et al (2019). Mengemukakan bahwa social media, electronic word of mouth memiliki hubungan yang positif terhadap purchase intention. Ketika konsumen akan membeli sesuatu, konsumen akan lebih memilih untuk membeli brand yang sudah dia ketahui sebelumnya melalui social media dan mengevaluasi kembali melalui aplikasi serta membaca review - review yang positif tentang produk yang hendak dibeli karena social media merupakan alat pemasaran serta alat komuniikasi bagi pembeli maupun penjual dimana diera industri 4.0 ini melalukan pembelian produk hanya menggunakan alat komunikasi smartphone (social media). Penulis dapat menyimpulkan pentingnya social media, electronic word of mouth terhadap mebangun minat beli. Kemudian Hipotesis Selanjutnya sesuai dengan Abzari, Et al., 2014 menemukan bahwa brand atittude secara signifikan mempengaruhi purchase intention. Brand atittude yang dikelola dengan baik akan menghasilkan efek yang positif terhadap sikap konsumen, dimana sikap tersebut akan mengarah kepada evaluasi keseluruhan yang positif bagi konsumen dalam melakukan pembelian maupun pembelian ulang.

Dengan demikian maka seluruh hipotesis penelitian ini terbukti dengan adanya data secara empiris. Purchase intention dapat diprediksi oleh social media, electronic word of mouth, brand atittude, maka dapat dilihat bahwa purchase intention dalam hal ini dapat dipengaruhi oleh social media disitus online shopee id yang menawarkan cara yang menyenangkan dan mudah untuk berinteraksi dengan para konsumen, electronic word of mouth yang baik, dan brand atittude yang dirasakan oleh konsumen pada situs online shopee id 


\section{KESIMPULAN DAN SARAN}

\section{Kesimpulan}

Dalam melakukan bisnis apapun, pelaku bisnis mengharapkan bisnis yang dimiliki dapat bertahan lama. Salah satu faktor penting dalam mewujudkannya adalah membangun minat pembelian konsumen terhadap produk yang ditawarkan pelaku bisnis. Tidak hanya mengandalkan kekuatan brand produk atau inovasi, tetapi perlu ada faktor lain yang mendukung social, electronic word of mouth dan brand atittude menjadi hal yang signifikan yang dapat berpengaruh terhadap berjalannya suatu bisnis.

Dukungan social media yang digunakan konsumen menbuat konsumen lebih mudah dalam mengambil keputusan. Demikian dengan electronic word of mouth yang baik akan membuat konsumen semakin yakin dalam menbuat keputusan dalam pembelian produk maupun merk yang ditawarkan, serta adanya dukungan brand atittude yang baik membentuk adanya rasa kepercayaan, rasa aman yang dirasakan konsumen yang menimbulkan dorongan emosional menbuat konsumen merasakan rasa suka atau tertarik terhadap merk maupun produk yang di tawarkan.

\section{Saran}

Peneliti menyarankan bagi manajerial di Situs Online Shopee Id agar selalu menperhatikan faktor social media, electronic word of mouth, brand attittude dalam kegiatan operasional di Situs Online Shopee Id. . Hal itu dikarenakan dikarenakan ketiga variabel tersebut diketahui mempunyai pengaruh dalam menciptakan purchase intention terhadap konsumen Situs Online Shopee Id

\section{IMPLIKASI MANAJERIAL}

Berkaitan dengan hasil penelitian, maka dapat disampaikan beberapa implikasi manajerial yang bisa diterapkan oleh perusahaan. Peneliti menyarakan pentingnya marketing sebuah brand melalui sosial media. Melalui media sosial perusahaan dapat berinteraksi dengan para konsumen dan calon konsumen secara langsung. Dengan menciptakan brand experience dari konsumen yang sesuai dengan keinginan konsumen. Peneliti juga menyarakan agar perusahaan selalu menciptakan rasa kepercayaan, aman serta nyaman bagi Konsumen Situs Online Shopee Id, Selalu dan tetap memberikan pelayanan terbaik kepada pelanggan seperti memberikan info yang detail tentang harga, kualitas produk, spesifikasi, dan garansi. Ketika konsumen mengetahui brand attitude Situs Online Shopee Id baik konsumen mampu melakukan pembelian produk dengan harga yang tercantum karena merasa ada beberapa faktor yang berbeda, unik untuk melakukan pembelian di Situs Online Shopee Id

\section{DAFTAR PUSTAKA}

Abzari, M., Ghassemi, R. A., \& Vosta, L. N. (2014). Analysing the effect of social media on brand attitude and purchase intention: the case of Iran Khodro company. Procedia Social and Behavioral Sciences, 143, 822-826

Indika, D., \& Jovita, C. (2017). Media sosial Instagram sebagai sarana promosi untuk meningkatkan minat beli konsumen. Jurnal Bisnis Terapan, 1(1).

Kudeshia, C., \& Kumar, A. (2017). Social eWOM: Does it affect the brand attitude and purchase intention of brands? Management Research Review.

Pengguna internet aktif di Indonesia pada akhir Januari 2020 (https://kominfo.go.id/), diakses tanggal 31 Agustus 2020

Prasad, S., Garg, A., \& Prasad, S. (2019). Purchase decision of generation Y in an online environment. Marketing Intelligence \& Planning.

Semuel, H., \& Setiawan, K. Y. (2018). Promosi melalui sosial media, brand awareness, purchase intention pada produk sepatu olahraga.

Shekhar, R. (2017). The Role of Ambient Ad Attitude and Brand Attitude as Predictors of Purchase Intention. National Conference on Marketing and Sustainable Development. 
Timpal, N., Lapian, \& Rate, P. V. (2016). Pengaruh Brand Awareness Dan Brand Attitude Terhadap Keputusan Pembelian Handphone Merek Nokia (Studi Kasus Pada Siswa Sma Dan Smk Di Kota Manado.

Widagdo, B., \& Saputri, M. E. (2017). Pengaruh Electronic Word Of Mouth Terhadap Purchase Intention Melalui Media Sosial Twitter Pada Chatime Indonesia. e-Proceeding of Management. 